\title{
Short Communication Coffee intake and CYPIA2*IF genotype predict breast volume in young women: implications for breast cancer
}

\author{
H Jernström ${ }^{*, 1,2}$, M Henningson', U Johansson' and H Olsson ${ }^{3}$

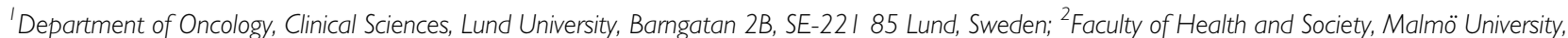 \\ SE-205 06 Malmö, Sweden; 'ंDepartment of Oncology and Cancer Epidemiology, Clinical Sciences, Lund University, Barngatan 2B, SE-22I 85 Lund, \\ Sweden
}

As breast volume may be associated with heart cancer risk, we studied the relationship between breast volume, CYPIA2* IF and coffee intake. Among healthy premenopausal non-hormone users, $3+$ cups per day was associated with lower volume only in C-allele carriers $\left(P_{\text {interaction }}=0.02\right)$, which is consistent with reports that coffee protects only $C$-allele carriers against breast cancer. British Journal of Cancer (2008) 99, I534- 1538. doi:I0.1038/sj.bjc.6604687 www.bjcancer.com

Published online 23 September 2008

(c) 2008 Cancer Research UK

Keywords: breast cancer; CYPIA2; coffee; breast volume; BRCAI/2; oral contraceptive

A recent study reported that coffee reduced the risk of breast cancer in BRCA1 carriers with the CYP1A2*1F C-allele but not in those with the $C Y P 1 A 2^{\star} 1 F$ A/A genotype (Kotsopoulos et al, 2007). Another study found significantly lower coffee consumption in sporadic breast cancer cases with at least one C-allele compared with the A/A genotype (Bågeman et al, 2008) in spite of the fact that coffee consumption is similar across $C Y P 1 A 2 * 1 F$ genotypes in the general population (Cornelis et al, 2006). Some studies (Vatten et al, 1990; Baker et al, 2006; Nkondjock et al, 2006; Ganmaa et al, 2008), but not all (Rosenberg et al, 1985; Vatten et al, 1990; McLaughlin et al, 1992; Stensvold and Jacobsen, 1994; Michels et al, 2002), have reported that moderate-to-high coffee consumption protects against breast cancer, though a mechanism is unknown. None of these studies took $C Y P 1 A 2^{\star} 1 F$ into account.

Coffee is metabolised by the CYP1A2 enzyme, which also plays a key role in oestrogen metabolism (Le Marchand et al, 1997; Lee et al, 2003). Coffee contains not only caffeine but also phytooestrogens that can interact with and even block the oestrogen receptor (Magee and Rowland, 2004). Women with high coffee intake and the highly inducible $C Y P 1 A 2 * 1 F$ A/A genotype (Sachse et al, 1999) have a high 2-hydroxyoestrone (2-OHE1) to $16 \alpha$-OHE1 ratio (Jernström et al, 2003; Bradlow et al, 2006; Klug et al, 2006). 2-Hydroxyoestrone is a weak oestrogen (Schneider et al, 1984), whereas $16 \alpha$-OHE1 is procarcinogenic (Telang et $a l, 1992)$. In line with this, we found that breast volume in breast cancer patients was significantly higher in women with a lower 2-OHE to $16 \alpha$-OHE1 ratio (Klug et al, 2006). Coffee also affects testosterone and SHBG levels (Ferrini and Barrett-Connor, 1996; Nagata et al, 1998). Although hormonal regulation of breast tissue has been extensively studied, little is known about hormones, genes, diet influence, density, size and diseases of the breast.

*Correspondence: Dr H Jernström; E-mail: helena.jernstrom@med.lu.se Received 10 July 2008; revised I September 2008; accepted I September 2008; published online 23 September 2008
Mammographic density is a strong risk factor for breast cancer (Boyd et al, 2005), the risk increasing with larger percentage density. The non-inducible CYP1A2* $1 F$ C-allele was associated with the percent density in normal-weight postmenopausal women not using hormone therapy (Takata et al, 2007). CYP1A2 enzyme activity has also been associated with density (Hong et al, 2004), and coffee induces CYP1A2 enzyme activity (Djordjevic et al, 2007). There is no direct correlation between breast density and size after adjustment for waist-to-hip ratio and BMI (Beijerinck et al, 1995). However, a larger breast size has been associated with increased breast cancer risk (Kato et al, 1995), especially in lean women (Kusano et al, 2006) or in women with proliferative breast disease (Dupont and Page, 1987). We therefore investigated whether coffee intake was associated with breast volume in young women and whether any association was modified by the $C Y P 1 A 2^{\star} 1 F$ genotype.

\section{MATERIALS AND METHODS}

A total of 269 young healthy Swedish women from breast cancer high-risk families volunteered to participate in this study between 1996 and 2006. The study population has previously been described in detail (Hietala et al, 2008). The Ethics Committee of Lund University approved the study. All women signed a written informed consent.

The questionnaire included questions on reproductive factors, the use of hormonal contraceptives, smoking, coffee consumption and so on. One large cup (approximately $300 \mathrm{ml}$ ) was counted as two traditional cups of coffee (approximately $150 \mathrm{ml}$ ). Blood samples and body measurements were collected both during menstrual cycle days 5-10 and days $18-23$. Breast volumes were measured while the woman was on her hands and knees with the breasts hanging down. The volume was approximated to a pyramid (base area $\times$ height $/ 3$ ). Total breast volume, that is the sum of the right and left breast volumes, was calculated in each visit.

Mutation testing of the BRCA1 and BRCA2 genes was not performed as part of this study and carrier status was obtained 
from the clinical records as previously described (Hietala et al, 2008). CYP $1 A 2^{\star} 1 F$ analysis (rs762551) PCR primers $5^{\prime}$-AGGTAT CAGCAGAAAGCCAGCAC and $5^{\prime}$-GCTGAGGGTTGAGATGGAGA CAT were used as described earlier (Bågeman et al, 2008). Thirtyeight samples were run in duplicate with $100 \%$ concordance.

Oestradiol was analysed with Elecsys system 1010/2010 in EDTA plasma. This system uses a competitive immunoassay with a polyclonal antibody directed towards $17-\beta$ oestradiol. Intra-assay variation ranged from 1.9 to $5.7 \%$ and the inter-assay variation varied from 2.3 to $6.2 \%$.

Testosterone, SHBG and progesterone in EDTA plasma were measured by electrochemiluminescent immunoassay by Elecsys 1010/2010 Modular analytics E170 analyser with the Roche Elecsys 1010/2010 (Roche Diagnostics, Mannheim, Germany). The intraassay variation was $2.5-6.8 \%$ for testosterone, $1.8-4.0 \%$ for SHBG and $1.8-4.8 \%$ for progesterone. Insulin-like growth factor $(I G F)-1$ was analysed in EDTA plasma with a radioimmunoassay method at Karolinska Hospital, Stockholm, Sweden as described earlier (Bang et al, 1991; Jernström et al, 2005). IGFBP-3 was analysed with the IMMULITE 2000 solid-phase enzyme-labelled chemiluminescent immunometric assay as described earlier (Jernström et al, 2006).

The statistical software programs SPSS13.0 and STATA 10.0 were used. Breast volumes and weights were not normally distributed and were transformed using the natural logarithm (ln). The $C Y P 1 A 2^{\star} 1 F$ genotype was classified into two groups (A/A or any $\mathrm{C}$-allele). An interaction term was calculated between $C Y P 1 A 2^{\star} 1 F$ and coffee $(3+$ cups per day). Multivariate linear regression analyses were performed to evaluate the interaction between $C Y P 1 A 2^{\star} 1 F$ and coffee on breast volume, and further adjusted for family clustering using the cluster option of the logistic command in STATA. Geometric means of standardised breast volumes and $95 \%$ prediction intervals were calculated. The breast volumes were standardised at age 29 years, weight $(\ln 67 \mathrm{~kg})$, non-smoking and nulliparity. Multivariate logistic regression was used to analyse the association between coffee and hormone and growth factor levels. A $P$-value of $<0.05$ was taken to be significant. All $P$-values were two sided.

\section{RESULTS}

Characteristics of the 269 women and $C Y P 1 A 2 * 1 F$ genotypes are presented in Table 1 . CYP $1 A 2^{\star} 1 F$ were available for 267 of the 269 women. $C Y P 1 A 2^{\star} 1 F$ did not differ according to $B R C A 1 / 2$ mutation status (Table 2). Coffee consumption did not significantly differ between the $C Y P 1 A 2^{\star} 1 F$ after adjusting for age and smoking.

Total breast volumes during menstrual cycle days 18-23 were available for 255 women who were not currently breast-feeding and without previous breast surgeries. Age-adjusted coffee consumption was positively associated with current smoking $(P<0.0001)$, but not with nulliparity or current hormonal contraception. Total breast volumes were positively associated with weight $(\beta=2.119 ; P<0.0001)$, but not with age, current hormonal contraception, nulliparity, current smoking or $C Y P 1 A 2^{*} 1 F$.

We stratified the women according to the use of hormonal contraceptives as this changes endogenous hormone levels (Jernström and Olsson, 1994; Jernström et al, 1997, 2005), influences breast volumes in nulliparous women (Jernström and Olsson, 1997) and reduces the CYP1A2 enzyme activity (Rietveld et al, 1984).

Among the non-users, of whom 145 had available breast volumes and $C Y P 1 A 2{ }^{\star} 1 F$ genotypes, the association between a moderate-to-high coffee consumption $(3+$ cups per day) and breast volume was significantly modified by $C Y P 1 A 2^{\star} 1 F$ genotype. Among women carrying at least one $\mathrm{C}$-allele, moderate-to-high consumption was associated with lower standardised breast volumes compared with low consumption $(896 v s 749 \mathrm{ml})$ whereas the standardised volumes were somewhat larger in women with moderate-to-high coffee consumption and the A/A genotype (797 vs $847 \mathrm{ml})\left(\beta=-0.303 ; P_{\text {interaction }}=0.02\right)$ (Figure 1$)$. The interaction remained significant after further adjustment for $B R C A 1 / 2$ mutation status $(\beta=-0.304 ; P=0.02)$ and after exclusion of women who currently smoked or used snuff $(\beta=-0.328$; $P=0.03)$. The women belonged to 105 different families. The interaction remained significant after adjustment for family clustering $(P=0.03)$.

Table I Baseline characteristics of the 269 women included in the study

\begin{tabular}{|c|c|c|c|}
\hline & All women $(N=269)$ & CYPIA2*IF A/A $(N=136)$ & CYPIA2*IF any $C(N=|3|)$ \\
\hline $\begin{array}{l}\text { Median (inter quartile range) or \% } \\
\text { Year of birth } \\
\text { Age at baseline (years) } \\
\text { Age at menarche (years) } \\
\text { Age at first birth in parous women (years) } \\
\text { Nulliparous (\%) } \\
\text { Ever smoker (\%) } \\
\text { Current smoker (\%) } \\
\text { Hormonal contraceptive use, ever (\%) } \\
\text { Current hormonal contraceptive use (\%) }\end{array}$ & $\begin{array}{c}1970(1965-1979) \\
29(24-34) \\
13(12-13.4) \\
24.5(22-28) \\
52 \\
42 \\
23 \\
92.5 \\
42\end{array}$ & $\begin{array}{c}1970(1965-1975) \\
29(24-33) \\
13(12-13) \\
24(23-27) \\
54 \\
41 \\
24 \\
93 \\
48\end{array}$ & $\begin{array}{c}1970(1964-1976) \\
30(24-36) \\
13(12-14) \\
25(22-28) \\
49 \\
42 \\
22 \\
92 \\
36\end{array}$ \\
\hline $\begin{array}{l}\text { Daily coffee intake, cups (\%) } \\
\text { None } \\
<1.0 \\
1.0-1.9 \\
2.0-2.9 \\
3.0-3.9 \\
4.0-4.9 \\
5.0-5.9 \\
6+\end{array}$ & $\begin{array}{c}(32.3) \\
(3.0) \\
(5.9) \\
(17.1) \\
(6.7) \\
(11.5) \\
(5.6) \\
(17.8)\end{array}$ & $\begin{array}{c}(31.6) \\
(2.9) \\
(7.6) \\
(16.9) \\
(5.1) \\
(15.4) \\
(4.4) \\
(16.2)\end{array}$ & $\begin{array}{c}(32.8) \\
(3.1) \\
(4.6) \\
(16.8) \\
(8.4) \\
(7.6) \\
(6.9) \\
(19.8)\end{array}$ \\
\hline $\begin{array}{l}\text { Height }(\mathrm{cm})^{b} \\
\text { Weight }(\mathrm{kg})^{b} \\
\text { BMI }\left(\mathrm{kg} / \mathrm{m}^{2}\right)^{\mathrm{b}} \\
\text { Waist-to-hip ratio } \\
\text { Total breast volume }(\mathrm{ml})^{\mathrm{c}}\end{array}$ & $\begin{array}{c}168(164-172) \\
64(58-74) \\
22.8(20.9-25.6) \\
0.76(0.73-0.80) \\
756(537-1101)\end{array}$ & $\begin{array}{c}168(164-173) \\
64(58-75) \\
22.7(20.8-26.2) \\
0.77(0.73-0.80) \\
711(555-1167)\end{array}$ & $\begin{array}{c}168(164-172) \\
65(58-73) \\
22.8(20.9-24.9) \\
0.75(0.73-0.80) \\
777(531-1040)\end{array}$ \\
\hline
\end{tabular}


Table 2 BRCA//2 mutation status and CYPIA2*IF genotypes in the women included in the study. CYPIA2*IF genotypes were missing for two women from non-BRCA//2 families

\begin{tabular}{|c|c|c|c|}
\hline & $\begin{array}{c}\text { All women } \\
\mathbf{N}=\mathbf{2 6 9} \\
\mathbf{N}\end{array}$ & $\begin{array}{c}\text { CYPIA2*IF A/A } \\
\begin{array}{c}N=136 \\
N(\%)\end{array}\end{array}$ & $\begin{array}{c}\text { CYPIA } 2 * I F \text { any C } \\
N=|3| \\
N(\%)\end{array}$ \\
\hline \multicolumn{4}{|l|}{ BRCA I } \\
\hline Carrier & 29 & I| (37.9) & $18(62 \mid)$ \\
\hline Non-carrier & 49 & $29(59.2)$ & $20(40.8)$ \\
\hline Not tested & 16 & $8(50.0)$ & $8(50.0)$ \\
\hline \multicolumn{4}{|l|}{ BRCA2 } \\
\hline Carrier & 7 & $4(57.1)$ & $3(42.9)$ \\
\hline Non-carrier & 7 & $6(85.7)$ & I (I4.3) \\
\hline Not tested & 4 & $3(75.0)$ & I (25.0) \\
\hline Non-BRCAl/2 & 112 & $55(50.0)$ & $55(50.0)$ \\
\hline Untested families & 45 & $20(44.4)$ & $25(55.6)$ \\
\hline
\end{tabular}

Breast volume in relation to $C Y P 1 A 2 * 1 F$ genotype and daily coffee consumption

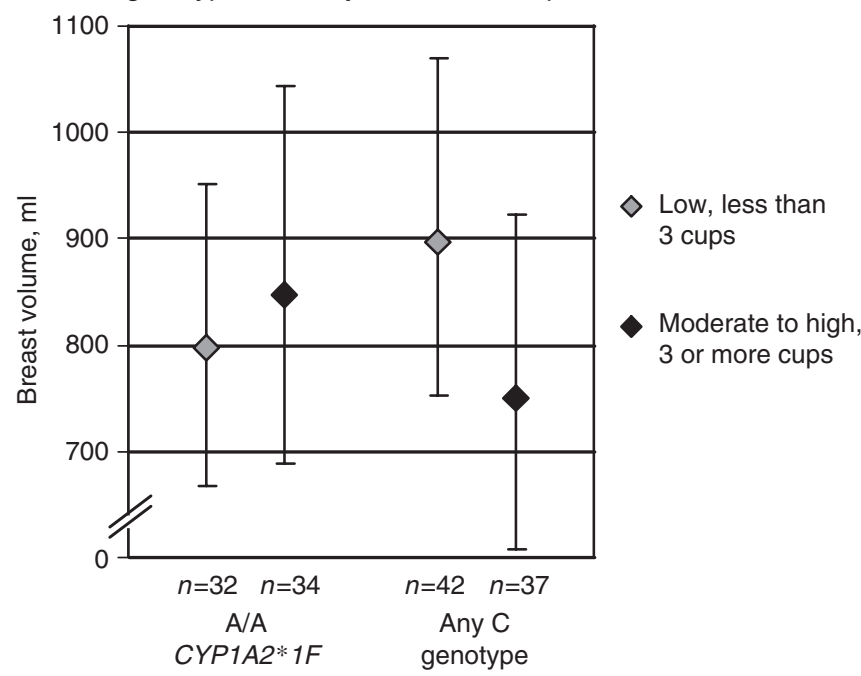

Figure I The figure shows the geometric means of the breast volumes in women according to their CYPIA2*IF genotype and coffee consumption. The breast volumes were standardised at age 29 years, body weight In $67 \mathrm{~kg}$, nulliparity and non-smoking. Ninty-five percent prediction intervals are presented. The interaction was significant $(P=0.02)$. Please note the broken y axis.

Plasma concentrations of oestradiol, progesterone, testosterone, SHBG, IGF-1 and IGFBP-3, obtained during the visit when the breast volumes were measured, were available for 139 women with data on breast volumes and $C Y P 1 A 2^{\star} 1 F$. In this subgroup, the interaction between coffee consumption and $C Y P 1 A 2^{\star} 1 F$ genotype on breast volume was somewhat stronger $(\beta=-0.341$; $\left.P_{\text {interaction }}=0.007\right)$ and became even stronger after further adjustment for hormone and growth factor levels $(\beta=-0.401$; $\left.P_{\text {interaction }}=0.002\right)$.

Among current hormonal contraceptive users, coffee consumption was not associated with breast volume and there was no significant interaction between coffee and $C Y P 1 A 2^{\star} 1 F$ on breast volume.

\section{DISCUSSION}

Our main finding was a significant interaction between coffee consumption, $C Y P 1 A 2^{\star} 1 F$ genotype and breast volume among young healthy women who did not use hormonal contraceptives. This interaction was mainly driven by the fact that a moderate-tohigh coffee intake was associated with lower breast volume in women with the $\mathrm{C}$-allele. No association between coffee and breast volumes was observed in women with the $C Y P 1 A 2{ }^{\star} 1 F \mathrm{~A} / \mathrm{A}$ genotype or in women who currently used hormonal contraception. As hormonal contraceptives lower the CYP1A2 enzyme activity (Rietveld et al, 1984), the latter observation was expected.

In this study, approximately $50 \%$ of the women carried the $C Y P 1 A 2 * 1 F$ A/A genotype, which is consistent with reported frequencies (Sachse et al, 1999; Nordmark et al, 2002). CYP1A2*1F is located in intron 1 and may not directly be associated with enzyme activity, but is rather linked to other polymorphisms with regulatory properties (Sachse et al, 1999). Coffee has been reported to predict $4 \%$ of the variation in CYP1A2 enzyme activity (Le Marchand et al, 1997).

In this study, breast volume was measured and approximated to a pyramid for practical reasons. A more exact procedure may have been to use water displacement, which we tried, but was impractical and less reproducible. Using bra cup size as a measurement of breast volume is less satisfactory, as cup-size labelling is not standardised (Ringberg et al, 2006).

Neither bra cup size nor breast volume reflects how much of the women's breast volume consists of breast parenchyma and how much is fat. A high BMI is positively correlated with larger cup sizes (Hall et al, 1999), which is in line with our findings. Others have reported that larger breasts consist of proportionally more fat and less parenchyma than smaller breasts in premenopausal women (Beijerinck et al, 1995; Kato et al, 1995). Most of our women were too young to have undergone mammography. We were thus unable to address whether coffee was associated with density, which is a stronger predictor of breast cancer risk than breast volume.

As coffee consumption was associated with lower breast volume among carriers of the $\mathrm{C}$-allele with little effect among homozygous A/A carriers, mechanisms other than the induction of the CYP1A2 enzyme may be at play. Caffeine is the only major compound in coffee that is known to be metabolised by CYP1A2 and the effect could be attributed to the prolonged exposure of caffeine among $\mathrm{C}$-allele carriers, as caffeine inhibits cell proliferation in mouse epidermal JB6 cells (Hashimoto et al, 2004).

Intake of caffeine has been positively associated with SHBG levels (Nagata et al, 1998) and inversely associated with bioavailable testosterone (Ferrini and Barrett-Connor, 1996), but $C Y P 1 A 2^{\star} 1 F$ was not analysed. In this study, we did not observe any significant associations between coffee intake and hormone and growth factor levels. However, bioavailable testosterone levels were positively associated with breast volumes in both groups (data not shown). In contrast to our earlier study, we did not find that hormonal contraception significantly influenced breast volume (Jernström and Olsson, 1997). In this study, measured hormone levels did not explain the observed interaction between coffee and $C Y P 1 A 2^{\star} 1 F$ on breast volume, although this became stronger after further adjustment for hormone levels.

In conclusion, the $C Y P 1 A 2^{\star} 1 F$ genotype significantly modified the relationship between coffee consumption and breast volume in non-users of hormonal contraception. It is likely that various compounds in coffee exert a direct effect on the breast epithelium. As breast volume is associated with breast cancer risk in lean women, our finding is compatible with earlier reports of a protective effect of coffee on breast cancer risk restricted to women with the $C Y P 1 A 2^{*} 1 F$ C-allele.

\section{ACKNOWLEDGEMENTS}

This study was supported by grants from Vetenskapsrådet, (The Swedish Research Council, K2001-27GX-14120-01A and K200868X-20802-01-3), the Medical Faculty in Lund, the Mrs. Berta 
Kamprad's Foundation, The Gunnar Nilsson Foundation, The South Swedish Health Care Region (Region Skåne), Lund Hospital Fund and the Swedish Cancer Society. We thank our research nurses Kerstin Nilsson, Monica Pehrsson, Karin Henriksson and Anita Schmidt-Casslén for their assistance with body measurements and blood drawing, and Johanna Wagenius, Johanna
Frenander, Helen Sundberg, Malin Sternby and Susanna Holmquist for their assistance with recruitment. Dr Åke Borg was responsible for $B R C A 1$ and $B R C A 2$ mutation testing. We thank Dr Pär-Ola Bendahl, biostatistician, for assistance with calculation of the prediction intervals and family-clustering models. We thank Dr Eric T Dryver for proofreading the manuscript.

\section{REFERENCES}

Bågeman E, Ingvar C, Rose C, Jernström H (2008) Coffee consumption and CYP1A2* $1 \mathrm{~F}$ genotype modify age at breast cancer diagnosis and estrogen receptor status. Cancer Epidemiol Biomarkers Prev 17: 895-901

Baker JA, Beehler GP, Sawant AC, Jayaprakash V, McCann SE, Moysich KB (2006) Consumption of coffee, but not black tea, is associated with decreased risk of premenopausal breast cancer. J Nutr 136: $166-171$

Bang P, Eriksson U, Sara V, Wivall IL, Hall K (1991) Comparison of acid ethanol extraction and acid gel filtration prior to IGF-I and IGF-II radioimmunoassays: improvement of determinations in acid ethanol extracts by the use of truncated IGF-I as radioligand. Acta Endocrinol (Copenh) 124: 620-629

Beijerinck D, van Noord PAH, Kemmeren JM, Seidell JC (1995) Breast size as a determinant of breast cancer. Int J Obes Relat Metab Disord 19: $202-205$

Boyd NF, Rommens JM, Vogt K, Lee V, Hopper JL, Yaffe MJ, Paterson AD (2005) Mammographic breast density as an intermediate phenotype for breast cancer. Lancet Oncol 6: 798-808

Bradlow HL, Jernström H, Sepkovic DW, Klug TL, Narod SA (2006) Comparison of plasma and urinary levels of 2-hydroxyestrogen and 16alpha-hydroxyestrogen metabolites. Mol Genet Metab 87: 135- 146

Cornelis MC, El-Sohemy A, Kabagambe EK, Campos H (2006) Coffee, CYP1A2 genotype, and risk of myocardial infarction. JAMA 295: $1135-1141$

Djordjevic N, Ghotbi R, Bertilsson L, Jankovic S, Aklillu E (2007) Induction of CYP1A2 by heavy coffee consumption in Serbs and Swedes. Eur J Clin Pharmacol 64: $381-385$

Dupont WD, Page DL (1987) Breast cancer risk associated with proliferative disease, age at first birth, and a family history of breast cancer. Am J Epidemiol 125: 769-779

Ferrini RL, Barrett-Connor E (1996) Caffeine intake and endogenous sex steroid levels in postmenopausal women. The Rancho Bernardo Study. Am J Epidemiol 144: 642-644

Ganmaa D, Willett WC, Li TY, Feskanich D, van Dam RM, Lopez-Garcia E, Hunter DJ, Holmes MD (2008) Coffee, tea, caffeine and risk of breast cancer: a 22-year follow-up. Int J Cancer 122: 2071-2076

Hall HI, Coates RJ, Uhler RJ, Brinton LA, Gammon MD, Brogan D, Potischman N, Malone KE, Swanson CA (1999) Stage of breast cancer in relation to body mass index and bra cup size. Int J Cancer 82: 23-27

Hashimoto T, He Z, Ma WY, Schmid PC, Bode AM, Yang CS, Dong Z (2004) Caffeine inhibits cell proliferation by G0/G1 phase arrest in JB6 cells. Cancer Res 64: 3344-3349

Hietala M, Olsson H, Jernström H (2008) Breast-feeding, milk production and prolactin levels among young healthy women from high-risk breast cancer families: implications for breast cancer risk. Familial Cancer 7: $221-228$

Hong CC, Tang BK, Rao V, Agarwal S, Martin L, Tritchler D, Yaffe M, Boyd NF (2004) Cytochrome P450 1A2 (CYP1A2) activity, mammographic density, and oxidative stress: a cross-sectional study. Breast Cancer Res 6: $\mathrm{R} 338-\mathrm{R} 351$

Jernström H, Klug TL, Sepkovic DW, Bradlow HL, Narod SA (2003) Predictors of the plasma ratio of 2-hydroxyestrone to 16alphahydroxyestrone among pre-menopausal, nulliparous women from four ethnic groups. Carcinogenesis 24: $991-1005$

Jernström H, Olsson H (1994) Suppression of plasma insulin-like growth factor-1 levels in healthy, nulliparous, young women using low dose oral contraceptives. Gynecol Obstet Invest 38: $261-265$

Jernström H, Olsson H (1997) Breast size in relation to endogenous hormone levels, body constitution, and oral contraceptive use in healthy nulligravid women aged 19-25 years. Am J Epidemiol 145: $571-580$

Jernström H, Olsson H, Borg $\AA$ (1997) Reduced testosterone, 17betaoestradiol, and sexual hormone binding globulin, and increased IGF-1 concentrations, in healthy nulligravid women aged 19-25 years who were first and/or second degree relatives to breast cancer patients. Eur J Cancer Prev 6: $330-340$

Jernström H, Sandberg T, Bågeman E, Borg Å, Olsson H (2005) Insulin-like growth factor-1 (IGF1) genotype predicts breast volume after pregnancy and hormonal contraception and is associated with circulating IGF-1 levels: implications for risk of early-onset breast cancer in young women from hereditary breast cancer families. Br J Cancer 92: $857-866$

Jernström H, Sellberg G, Borg A, Olsson H (2006) Differences in IGFBP-3 regulation between young healthy women from BRCAX families compared to those belonging to BRCA1/2 families. Eur J Cancer Prev 15: $233-241$

Kato I, Beinart C, Bleich A, Su S, Kim M, Toniolo PG (1995) A nested casecontrol study of mammographic patterns, breast volume, and breast cancer (New York City, NY, United States). Cancer Causes Control 6: $431-438$

Klug TL, Bågeman E, Ingvar C, Rose C, Jernström H (2006) Moderate coffee and alcohol consumption improves the estrogen metabolite profile in adjuvant treated breast cancer patients: a pilot study comparing pre- and post-operative levels. Mol Genet Metab 89: $381-389$

Kotsopoulos J, Ghadirian P, El-Sohemy A, Lynch HT, Snyder C, Daly M, Domchek S, Randall S, Karlan B, Zhang P, Zhang S, Sun P, Narod SA (2007) The CYP1A2 genotype modifies the association between coffee consumption and breast cancer risk among BRCA1 mutation carriers. Cancer Epidemiol Biomarkers Prev 16: 912 -916

Kusano AS, Trichopoulos D, Terry KL, Chen WY, Willett WC, Michels KB (2006) A prospective study of breast size and premenopausal breast cancer incidence. Int J Cancer 118: 2031-2034

Le Marchand L, Franke AA, Custer L, Wilkens LR, Cooney RV (1997) Lifestyle and nutritional correlates of cytochrome CYP1A2 activity: inverse associations with plasma lutein and alpha-tocopherol. Pharmacogenetics 7: $11-19$

Lee AJ, Cai MX, Thomas PE, Conney AH, Zhu BT (2003) Characterization of the oxidative metabolites of 17beta-estradiol and estrone formed by 15 selectively expressed human cytochrome p450 isoforms. Endocrinology 144: $3382-3398$

Magee PJ, Rowland IR (2004) Phyto-oestrogens, their mechanism of action: current evidence for a role in breast and prostate cancer. Br J Nutr 91: $513-531$

McLaughlin CC, Mahoney MC, Nasca PC, Metzger BB, Baptiste MS, Field NA (1992) Breast cancer and methylxanthine consumption. Cancer Causes Control 3: 175-178

Michels KB, Holmberg L, Bergkvist L, Wolk A (2002) Coffee, tea, and caffeine consumption and breast cancer incidence in a cohort of Swedish women. Ann Epidemiol 12: 21 - 26

Nagata C, Kabuto M, Shimizu H (1998) Association of coffee, green tea, and caffeine intakes with serum concentrations of estradiol and sex hormone-binding globulin in premenopausal Japanese women. Nutr Cancer 30: $21-24$

Nkondjock A, Ghadirian P, Kotsopoulos J, Lubinski J, Lynch H, Kim-Sing C, Horsman D, Rosen B, Isaacs C, Weber B, Foulkes W, Ainsworth P, Tung N, Eisen A, Friedman E, Eng C, Sun P, Narod SA (2006) Coffee consumption and breast cancer risk among BRCA1 and BRCA2 mutation carriers. Int J Cancer 118: $103-107$

Nordmark A, Lundgren S, Ask B, Granath F, Rane A (2002) The effect of the $\mathrm{CYP} 1 \mathrm{~A} 2{ }^{*} 1 \mathrm{~F}$ mutation on CYP1A2 inducibility in pregnant women. $\mathrm{Br} J$ Clin Pharmacol 54: 504-510

Rietveld EC, Broekman MM, Houben JJ, Eskes TK, van Rossum JM (1984) Rapid onset of an increase in caffeine residence time in young women due to oral contraceptive steroids. Eur J Clin Pharmacol 26: $371-373$ 
Coffee intake and CYPIA2*IF genotype predict breast volume $\mathrm{H}$ Jernström et al

Ringberg A, Bågeman E, Rose C, Ingvar C, Jernström H (2006) Of cup and bra size: Reply to a prospective study of breast size and premenopausal breast cancer incidence. Int J Cancer 119: 2242-2243

Rosenberg L, Miller DR, Helmrich SP, Kaufman DW, Schottenfeld D, Stolley PD, Shapiro S (1985) Breast cancer and the consumption of coffee. Am J Epidemiol 122: 391-399

Sachse C, Brockmoller J, Bauer S, Roots I (1999) Functional significance of a $\mathrm{C} \rightarrow \mathrm{A}$ polymorphism in intron 1 of the cytochrome $\mathrm{P} 450 \mathrm{CYP} 1 \mathrm{~A} 2$ gene tested with caffeine. Br J Clin Pharmacol 47: 445-449

Schneider J, Huh MM, Bradlow HL, Fishman J (1984) Antiestrogen action of 2-hydroxyestrone on MCF-7 human breast cancer cells. J Biol Chem 259: $4840-4845$
Stensvold I, Jacobsen BK (1994) Coffee and cancer: a prospective study of 43,000 Norwegian men and women. Cancer Causes Control 5: 401-408

Takata Y, Maskarinec G, Le Marchand L (2007) Breast density and polymorphisms in genes coding for CYP1A2 and COMT: the Multiethnic Cohort. BMC Cancer 7: 30

Telang NT, Suto A, Wong GY, Osborne MP, Bradlow HL (1992) Induction by estrogen metabolite 16 alpha-hydroxyestrone of genotoxic damage and aberrant proliferation in mouse mammary epithelial cells. $J$ Natl Cancer Inst 84: 634-638

Vatten LJ, Solvoll K, Loken EB (1990) Coffee consumption and the risk of breast cancer. A prospective study of 14593 Norwegian women. $\mathrm{Br} J$ Cancer 62: 267-270 